\title{
OPEN Diamine vapor treatment of viscoelastic graphene oxide liquid crystal for gas barrier coating
}

\author{
Seung Eun Choi ${ }^{1}$, Sung-Soo Kim², Eunji Choi ${ }^{1}$, Ji Hoon Kim¹, Yunkyu Choi ${ }^{1}$, Junhyeok Kang ${ }^{1}$,
} Ohchan Kwon ${ }^{1} \&$ Dae Woo Kim ${ }^{1 \bowtie}$

\begin{abstract}
A layered graphene oxide/ethylenediamine (GO/EDA) composite film was developed by exposing aqueous $\mathrm{GO}$ liquid crystal (GOLC) coating to EDA vapor and its effects on the gas barrier performance of GO film were systematically investigated. When a GO/EDA coating with a thickness of approximately $1 \mu \mathrm{m}$ was applied to a neat polyethylene terephthalate (PET) film, the resultant film was highly impermeable to gas molecules, particularly reducing the gas permeance up to $99.6 \%$ for $\mathrm{He}$ and $98.5 \%$ for $\mathrm{H}_{2}$ in comparison to the neat PET film. The gas barrier properties can be attributed to the long diffusion length through stacked GO nanosheets. The EDA can crosslink oxygen-containing groups of GO, enhancing the mechanical properties of the GO/EDA coating with hardness and elastic modulus values up to 1.14 and $28.7 \mathrm{GPa}$, respectively. By the synergistic effect of the viscoelastic properties of GOLC and the volatility of EDA, this coating method can be applied to complex geometries and EDA intercalation can be spontaneously achieved through the scaffold of the GOLC.
\end{abstract}

Impermeable barrier coatings are essential in various applications, such as food packaging, electronic devices, energy storage, membrane, and hydrogen storage ${ }^{1-4}$. Among the various impermeable materials, graphene is an ideal barrier due to its high mechanical strength, chemical stability, and most importantly, its impermeability to all gas molecules even for helium and hydrogen ${ }^{5}$. Graphene is also intrinsically flexible, stretchable, and transparent owing to its atomic-scale thickness ${ }^{6,7}$. Considering all these advantages, single-layer graphene synthesized by chemical vapor deposition (CVD) was deposited on polymeric substrates or stacked in the form of a multilayer graphene film ${ }^{8}$. However, the transfer of CVD graphene onto a large area without the formation of cracks is challenging, and the generation of point defects and grain boundaries is unavoidable during the CVD process ${ }^{9}$. In addition, the metal catalyst (usually $\mathrm{Cu}, \mathrm{Ni}$, or alloy foil) needs to be removed by an acidic etchant such as $\mathrm{FeCl}_{3}$, raising critical issues in terms of environmental impact and fabrication costs ${ }^{6}$. Therefore, although CVD graphene could be an ideal gas barrier material, the deposition of defect-free graphene on a large scale onto various substrate geometries remains challenging.

As an alternative, graphene nanosheets including few-layer graphene flakes, graphene oxide (GO), and reduced graphene oxide ( $\mathrm{rGO}$ ) have been frequently hybridized with polymers, inorganic particles, and organic molecules ${ }^{10-12}$. The incorporation of impermeable fillers with high aspect ratios effectively enhances the gas barrier performance by increasing the diffusion length of permeating gas molecules ${ }^{13}$. Abundant oxygen-containing groups of graphene derivatives are also beneficial to the functionalization of the graphene surface, to enhance the solubility in organic solvents, and to improve the miscibility of graphene with polymer matrix ${ }^{14}$. More importantly, the preparation of graphene derivatives, particularly GO, can be scalable to satisfy the demand of nanofillers for composite preparation ${ }^{4,15-19}$. Nonetheless, the high loading of graphene fillers in the polymer matrix is hindered by the aggregation and restacking induced by van der Waals interactions between graphene sheets ${ }^{20-22}$.

The stacked structure of GO sheets in the form of a laminated film on the polymeric substrate has been suggested as a promising method to solve this problem. While the GO coating is permeable to water molecules, it can block the permeation of all gas molecules ${ }^{23}$. In addition, the GO layer becomes impermeable to both water and gas molecules after chemical reduction ${ }^{24}$. To achieve the barrier properties of stacked GO films, several fabrication methods have been suggested such as spin-coating ${ }^{25}$, spray-coating ${ }^{26}$, vacuum filtration ${ }^{27,28}$, bar-coating $^{29,30}$, slot-die coating ${ }^{31}$, and layer-by-layer (LBL) assembly ${ }^{3,32}$. LBL assembly is particularly effective owing to its numerous advantages; it allows the easy control of the GO coating thickness in the nanometer-scale with highly

${ }^{1}$ Department of Chemical and Biomolecular Engineering, Yonsei University, Yonsei-ro 50, Seodaemun-gu, Seoul 03722, Republic of Korea. ${ }^{2}$ Carbon Composite Materials Research Center, Korea Institute of Science and Technology, 92 Chudong-ro Bongdong-eup, Wanju-gun, Jeollabuk-do 55324, Republic of Korea. ${ }^{\square}$ email: audw1105@yonsei.ac.kr 

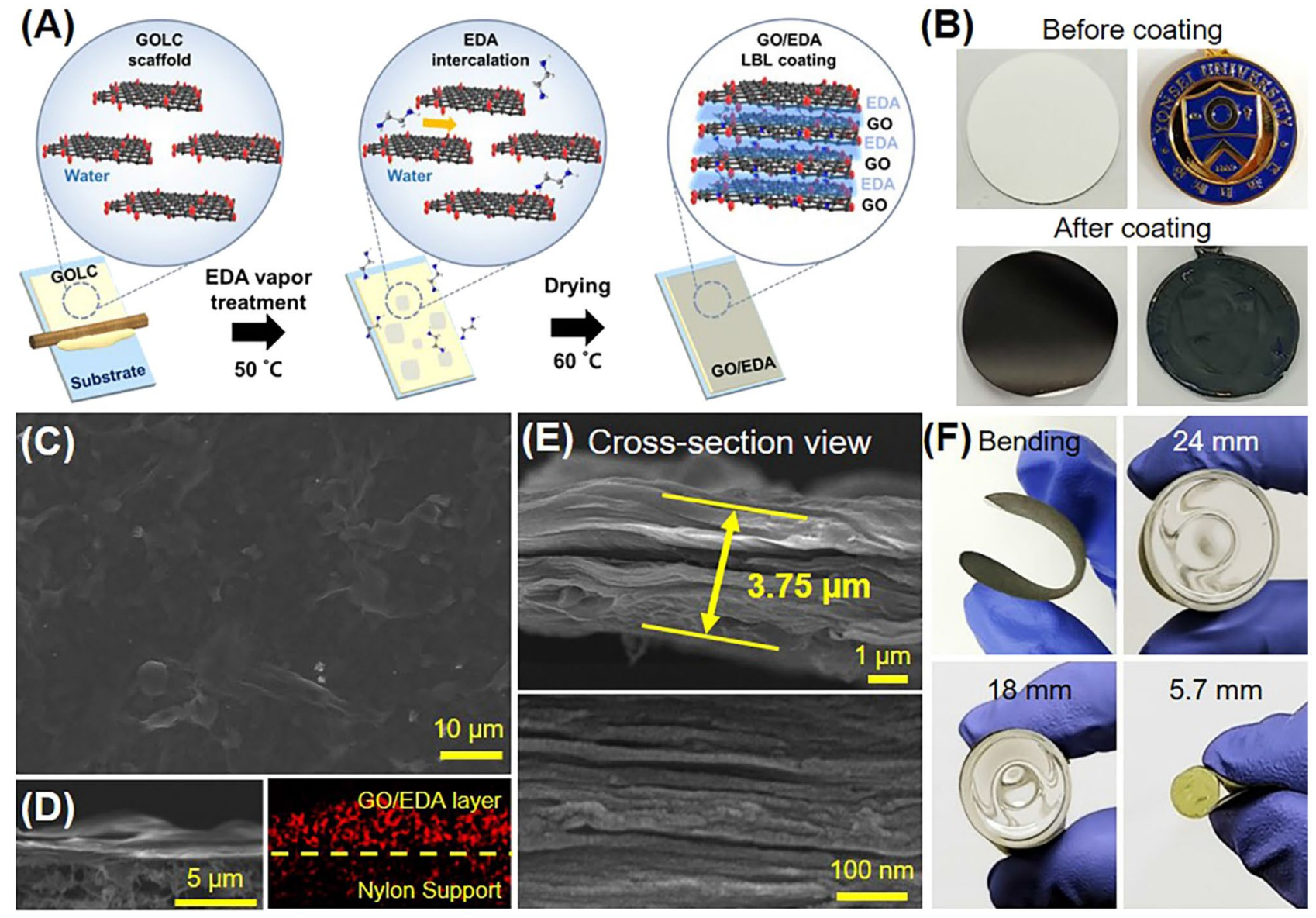

Figure 1. (A) Schematic illustration of GO/EDA coating procedure on the target substrate. (B) Photographic images of a nylon substrate and a souvenir before and after GO/EDA coating. (C,D) Top-view, and crosssectional SEM images of a GO/EDA coating on a nylon substrate. The right image of (D) is EDS mapping image for nitrogen. (E) Magnified cross-sectional SEM images of GO/EDA coating. (F) Bending test of GO/EDA coated a nylon substrate at several bending diameters. The EDA exposure time was $1 \mathrm{~h}$.

aligned GO nanosheets, and can be applied to complex geometries with excellent gas barrier performances ${ }^{32-34}$. However, the fabrication procedure is laborious, therefore, the development of an efficient fabrication procedure is imperative to meet the industry requirements ${ }^{35}$.

Herein, a layered GO/EDA composite coating with gas barrier properties was achieved by exposing aqueous GO liquid crystal (GOLC) coating to EDA vapor, utilizing the volatility of EDA. The diffusion of EDA was highly facilitated into the interlayer and scaffold of GOLC and the amounts of intercalated EDA molecules can be precisely controllable by adjusting the exposure time. The intercalation mechanism and the EDA structure between GO nanosheets were thoroughly examined to the exposure time of EDA vapor. In addition, we performed a systematic analysis of the changes in mechanical properties and gas permeation of the GO/EDA coatings according to the amount of EDA in the designed film.

\section{Results and discussion}

The procedure for GO/EDA coating on a target surface is portrayed in Fig. 1A and the corresponding photographic images are shown in Supplementary Fig. S1. GOLC with a concentration of $30 \mathrm{mg} / \mathrm{mL}$ was prepared by dispersing GO in water via sonication, which is a typical method to induce the lyotropic LC phase of GO in an aqueous solvent ${ }^{36}$. The gel-like GO solution was distributed on a target substrate using a bar-coater. The thickness of GOLC is adjustable by changing the gap between the bar and the substrate. In this study, the thickness of the GOLC coating was fixed at $180 \mu \mathrm{m}$. A porous nylon substrate (pore size of $0.1 \mu \mathrm{m}$ ) was used as a substrate to demonstrate the feasibility of our coating method on surfaces with complex structures. A 75- $\mu$ m-thick PET film was used for the gas permeation test (Supplementary Fig. S2). The GOLC coated substrate was placed in the center of a petri dish and $0.5 \mathrm{~mL}$ of $75 \% \mathrm{EDA}$ aqueous solution was spread around it. Then, it was kept in an oven at $50{ }^{\circ} \mathrm{C}$ for the desired time. Higher temperatures are inappropriate because the water in the GOLC coating may dry too quickly. After a certain time under EDA vapor treatment, the GO/EDA coated substrate was dried at $25^{\circ} \mathrm{C}$ to remove excess water, resulting in the formation of a dense GO/EDA coating. The GO/ EDA coating can be applied to various objects, such as a more complex object like a school souvenir as shown in Fig. 1B. We also want to emphasize the advantage of using EDA vapor for the treatment of GOLC. While our previous work based on the EDA solution immersion is effective for the treatment of flat type coating or small 
(A)

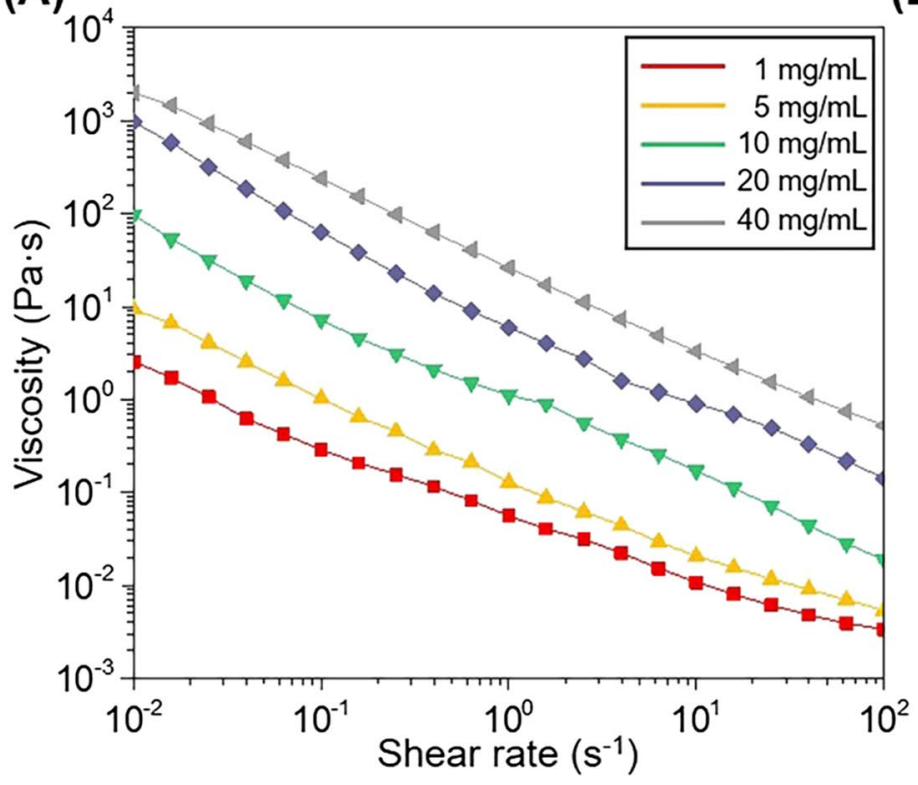

(B)

$10 \mathrm{mg} / \mathrm{mL}$
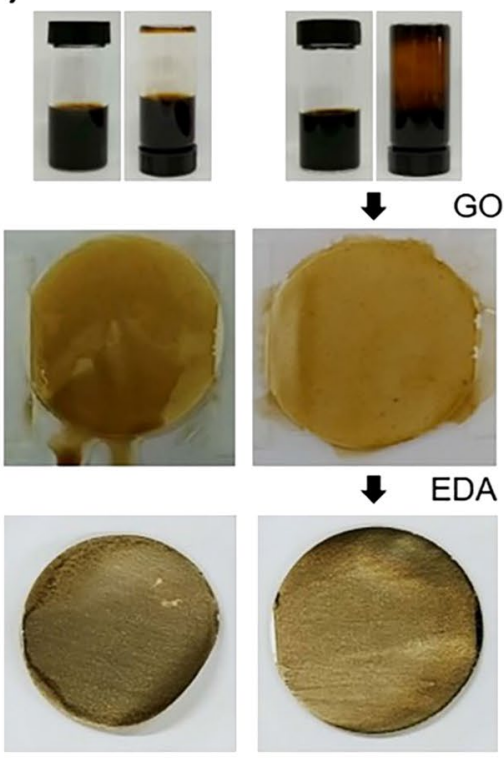

$20 \mathrm{mg} / \mathrm{mL}$

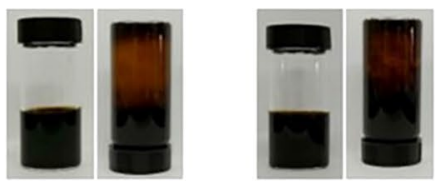

coating

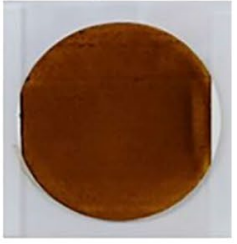

$\checkmark$ EDA exposure
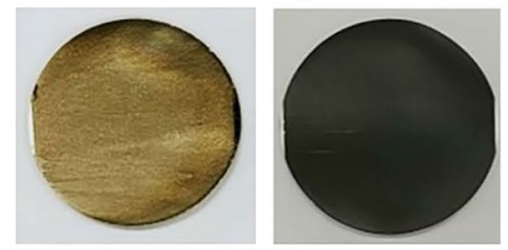

Figure 2. Viscoelastic rheological properties of the GO solution. (A) Viscosity of GO solution as a function of shear rate and concentration. (B) GO/EDA coating quality depending on the concentration of the GO solution. The EDA exposure time was $1 \mathrm{~h}$.

objective, using EDA solution treatment has the limitation in applying the coating in large-size objects such as hydrogen cylinders owing to the possibility of the GOLC coating delamination during the immersion process ${ }^{33}$. Therefore, EDA vapor treatment was chosen for the crosslinking reagent, because it is beneficial for applying in scale-up coating and reducing laborious and time-consuming process.

To verify the feasibility of our method to produce a uniform GO/EDA coating layer, SEM images were acquired from the GO/EDA coating with $1 \mathrm{~h}$ exposure to the EDA vapor (Fig. 1C,D). A uniform GO/EDA coating layer was observed on the nylon substrate (Fig. 1C). The GO sheets were stacked parallel to the substrate (Fig. 1D,E) because the shear coating process aligned the GOLC scaffold in parallel with the substrate ${ }^{33}$. The EDS mapping of nitrogen marked with red color showed the homogeneous distribution of amine groups, indicating uniform diffusion of EDA molecules into the inner regions of the GOLC. A round morphology was observed between the GO sheets in the magnified cross-sectional SEM images of GO/EDA (Fig. 1E), while the edge of neat GO sheets was sharp (Supplementary Fig. S3). This denoted the presence of EDA surrounding each GO layer, which is stably adhered to the graphene surface even in the high vacuum conditions during the SEM measurements. As shown in the bending test, the GO/EDA coating on the nylon substrate was highly bendable and could be bent to the $5.7 \mathrm{~mm}$ diameter of a glass rod (Fig. 1F). This is due to the intrinsic flexible nature of graphene, and this flexibility could be critical in applications such as flexible electronics, food packaging, and gas storage.

The viscoelastic rheological properties are essential for uniform coating of GOLC on complex geometries by using the shear-coating method and to preserve the shape of the GOLC coating during EDA vapor exposure ${ }^{33,36,37}$. Primarily, the viscoelastic properties of GOLC were investigated by measuring the GOLC viscosity as a function of the shear rate and concentration (Fig. 2A). The viscosity of GOLC gradually increased with the concentration from 1 to $40 \mathrm{mg} / \mathrm{mL}$. Particularly, the viscosity of GOLC reached $1 \times 10^{3}$ and $3 \times 10^{3} \mathrm{~Pa} \cdot \mathrm{s}$ for 20 and $40 \mathrm{mg} /$ $\mathrm{mL}$, respectively, in static conditions. However, the viscosity of $40 \mathrm{mg} / \mathrm{mL}$ GOLC spontaneously decreased to $9 \times 10^{-1} \mathrm{~Pa} \cdot \mathrm{s}$ at a shear rate of $100 \mathrm{~s}^{-1}$, indicating gel-like and shear-thinning viscoelastic behavior; therefore, the viscosity is highly influenced by the shear rate $33,38,39$.

The coating process was also conducted with GO solutions of 10,20 , and $40 \mathrm{mg} / \mathrm{mL}$ (Fig. 2B). The photographic images of the vials containing the GO solutions show that the $10 \mathrm{mg} / \mathrm{mL}$ solution was watery, while GO solutions of $20 \mathrm{mg} / \mathrm{mL}$ and $40 \mathrm{mg} / \mathrm{mL}$ adhered to the wall of the vials even after turning the vial upside down. This indicates that a solid-like behavior of the GO solutions can be observed at the higher concentrations, as demonstrated by the rheology study shown in Fig. 2A. To reveal the importance of a high viscosity GOLC, the nylon substrates with GOLC coating were tilted at $45^{\circ}$ as shown in the second row of the images of Fig. $2 \mathrm{~B}$. As expected, the GOLC coating was only preserved for the $40 \mathrm{mg} / \mathrm{mL}$ solution, while for lower concentrations the coating flowed to the bottom. Therefore, a higher concentration of GOLC produces better quality GO/EDA films by preserving the shape of the GOLC coating during EDA exposure (the third row of the images of Fig. 2B). This observation is particularly important when GO/EDA coating is applied to objects with a three-dimensional morphology and tilted surfaces such as gas storage tanks.

XRD analysis was conducted to examine the intercalation of EDA into the GOLC scaffold and its interlayer structure (Fig. 3, Supplementary Fig. S4). Figure 3A displays the XRD patterns of GO/EDA coating and Fig. 3B summarizes the corresponding interlayer distance. The interlayer distance of GO was $7.95 \AA$, which is in agreement with the literature ${ }^{23}$. The interlayer distance of the GO/EDA coating was $8.24 \AA$ after 5 min of EDA 
(A)

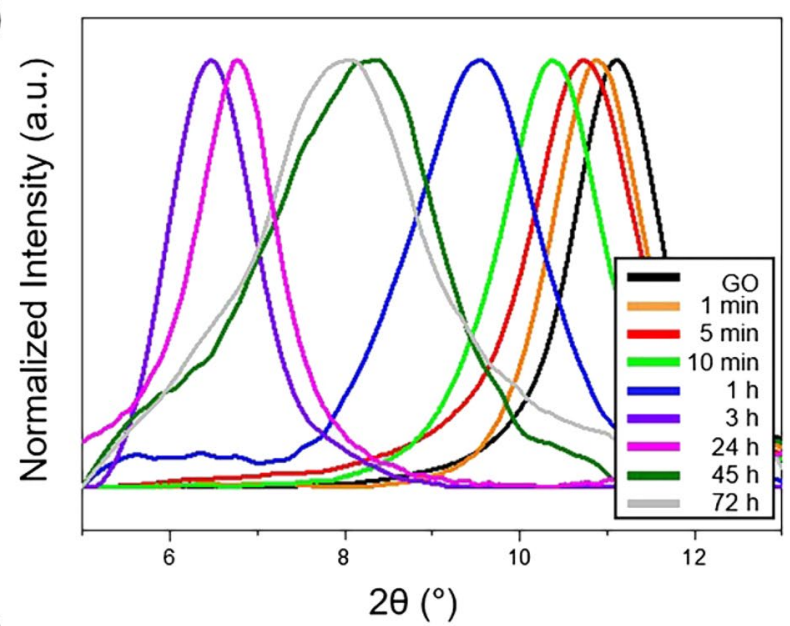

(B)

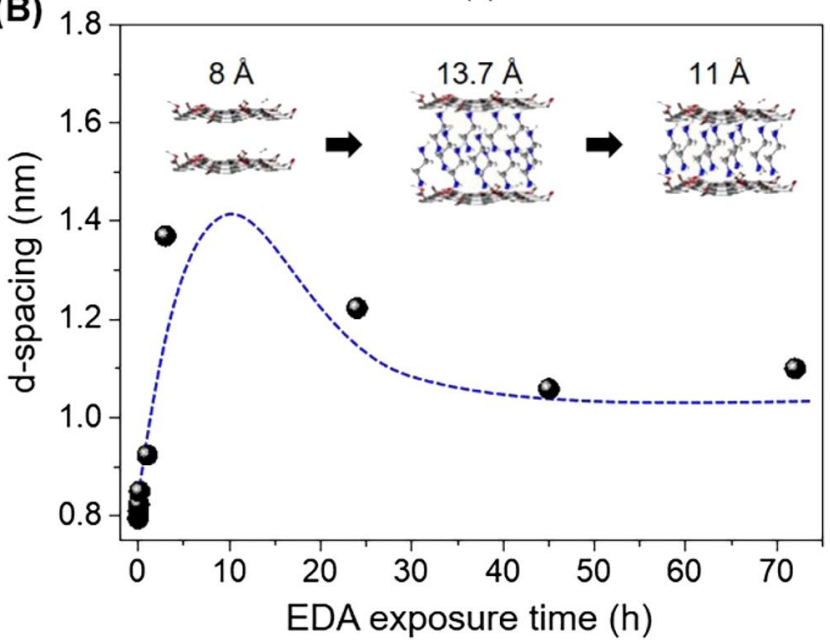

Figure 3. (A) XRD patterns of GO/EDA as a function of EDA vapor exposure time. (B) Corresponding d-spacing of GO/EDA.

exposure, indicating the spontaneous intercalation of EDA into the GOLC scaffold. The value increased to $9.24 \AA$ after $1 \mathrm{~h}$ of EDA exposure and further increased to $13.7 \AA$ after exposure for $3 \mathrm{~h}$. We want to emphasize that the expanded interlayer spacing is not by the presence of water because all samples were fully dried at $60^{\circ} \mathrm{C}$ for $24 \mathrm{~h}$ before XRD measurement and neat GO did not show similar expansion of interlayer spacing. The interlayer distance was reduced to $13.1 \AA$ after $1 \mathrm{~d}$ of exposure. After $3 \mathrm{~d}$ of exposure, the interlayer distance was further decreased and saturated to $11.0 \AA$ at a longer EDA exposure time of $72 \mathrm{~h}$, which is the typical interlayer distance of GO cross-linked with $\mathrm{EDA}^{40}$. Considering the length of an EDA molecule (around $3.7 \AA$ ) and the thickness of a graphene layer $(3.4 \AA)^{21}$, it can be assumed that a double layer of EDA molecules exists between the GO sheets at the low EDA exposure times as described in the inserted scheme of Fig. 3B because excessive EDA can diffuse into the scaffold of GOLC spontaneously. The rearrangement of the EDA molecules may occur at exposure times over $3 \mathrm{~h}$ as some of the EDA is possibly consumed in the formation of crosslinking with oxygen-containing groups of GO or unreacted EDA molecules are removed from the composite system with time ${ }^{33,40}$. We believe the reduction of GO is not the main reason for the thickness decrease because most of the oxygen-containing groups are detected by XPS even after EDA treatment, which we will deliberate in detail below. Similarly, the increasing thickness of the GO/EDA coating with increased EDA exposure time was observed in the SEM images of the GO/EDA coating (Supplementary Fig. S3). The influence of EDA exposure time on the mechanical and gas barrier properties of the GO/EDA coating will be discussed later.

The chemical structure of the GO/EDA coating was examined using water contact angle measurements, XPS, FT-IR (Fig. 4), and Raman spectroscopy (Supplementary Fig. S5). The water contact angle of GO was $55^{\circ}$ and gradually decreased to $39^{\circ}$ with increasing EDA exposure time (Fig. 4A). The more hydrophilic surface of the $\mathrm{GO} / \mathrm{EDA}$ coating can be ascribed to the amine groups of EDA molecules that are bonded to the surface of GO as considering the protonation of amine groups in the presence of water ${ }^{40}$. The FT-IR spectra confirmed the variation of functional groups in $\mathrm{GO}$ and $\mathrm{GO} / \mathrm{EDA}$ coatings, particularly the $\mathrm{C}=\mathrm{O}$ stretching of amide $\left(1710 \mathrm{~cm}^{-1}\right)$ and $\mathrm{C}-\mathrm{N}$ stretching $\left(1340 \mathrm{~cm}^{-1}\right)$ (Fig. $\left.4 \mathrm{~B}\right)$. The $\mathrm{C}=\mathrm{O}$ stretching peak became clear as the EDA exposure time increased. This tendency was observed because the amine groups of the EDA and the oxygen-containing groups 
(A)
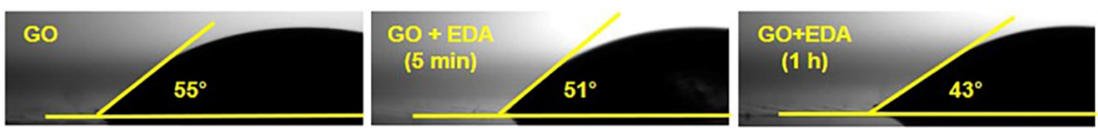

GO+EDA

(B)

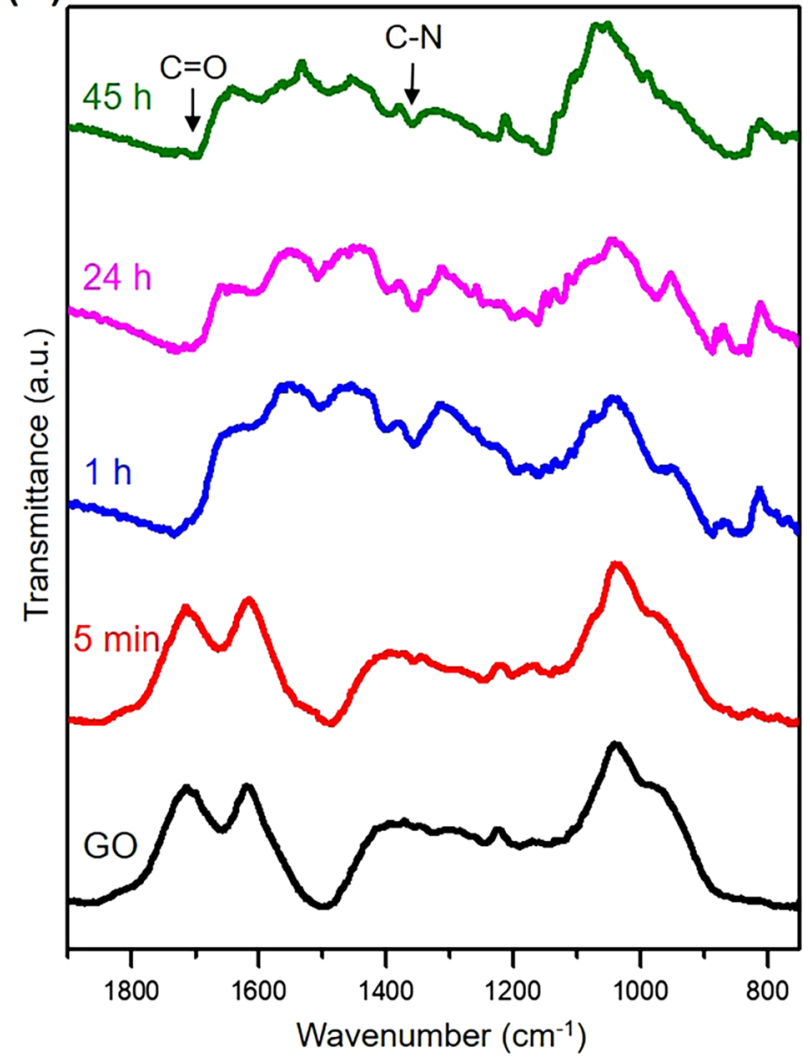

(C)
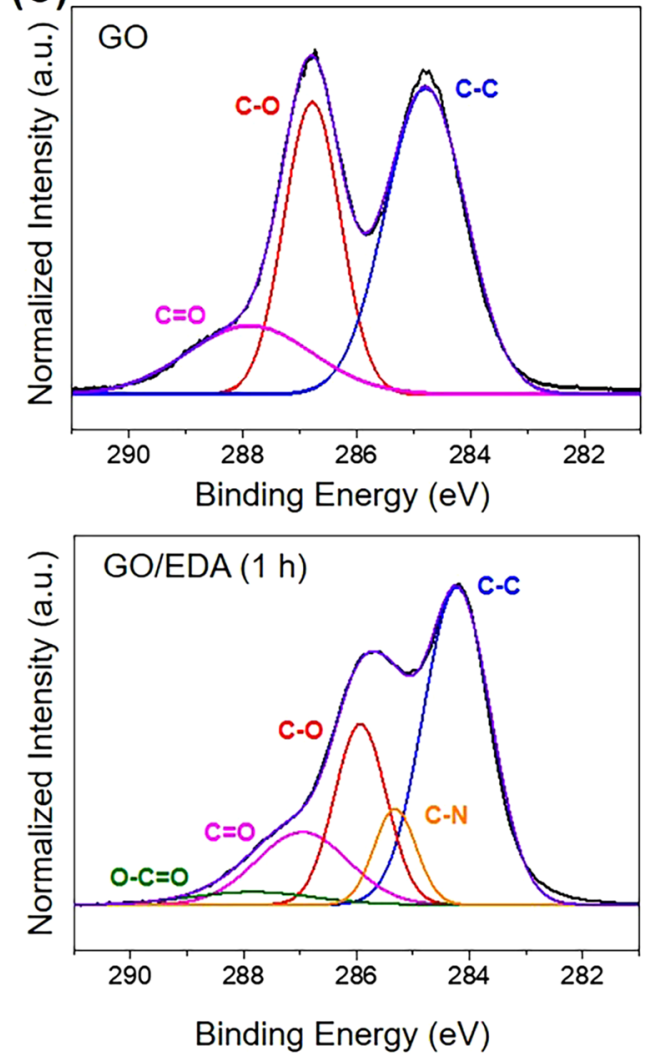

Figure 4. (A) Water contact angles and (B) FT-IR spectra of GO and GO/EDA film depending on the EDA exposure time. (C) XPS C1s spectra of GO and GO/EDA. EDA was exposed for $1 \mathrm{~h}$.

of GO form an amide bond ${ }^{33}$. At the same time, the $\mathrm{C}-\mathrm{N}$ stretching peak began to appear, which implies the presence of EDA molecules in the GO/EDA coating.

Figure 4C shows the $\mathrm{C} 1 \mathrm{~s}$ spectra of $\mathrm{GO}$ and $\mathrm{GO} / \mathrm{EDA}$ coating. Typical oxygen-containing groups of $\mathrm{C}-\mathrm{O}$ $(286.8 \mathrm{eV})$ and $\mathrm{C}=\mathrm{O}(287.9 \mathrm{eV})$ were detected in the circumstance of the $\mathrm{GO}$ coating. A new $\mathrm{C}-\mathrm{N}$ peak appeared at $285.3 \mathrm{eV}$ after EDA treatment due to the presence of both unreacted amine groups and the amide bonding of EDA. Also, the intensity of the $\mathrm{C}-\mathrm{O}$ and $\mathrm{C}=\mathrm{O}$ peaks in the XPS spectra of GO/EDA $(1 \mathrm{~h})$ was relatively lower compared to that of the GO peaks because of the partial reduction of oxygen groups in the presence of the alkaline $\mathrm{EDA}^{40}$. The reduction mechanism can be a nucleophilic ring-opening reaction in the presence of amines, which means that the amine groups disconnect the oxygen moieties and remain $\mathrm{sp}^{2}$ hybridized carbon bonding ${ }^{41}$. This partial reduction reaction between GO and EDA was reconfirmed by the Raman spectra, which showed an increased $\mathrm{I}_{\mathrm{D}} / \mathrm{I}_{\mathrm{G}}$ ratio as the EDA exposure time increased (Supplementary Fig. S5). It is known that the $\mathrm{I}_{\mathrm{D}} / \mathrm{I}_{\mathrm{G}}$ peak ratio of $\mathrm{GO}$ increases by chemical reduction due to the generation of dense and small $\mathrm{sp}^{2}$ carbon domains $\mathrm{s}^{21}$. Based on the aforementioned results, we conclude that EDA crosslinks the GO sheets and also partially reduces $\mathrm{GO}$, thus, the reduction becomes significant at longer EDA exposure times. However, we want to notice that the EDA treatment conditions are not enough to fully reduced GO into rGO as reflected by the presence of oxygen groups in GO/EDA samples (Fig. 4B,C).

The mechanical properties of the GO/EDA coating with various EDA exposure times were measured using the nanoindentation method and compared with a neat GO film (Fig. 5A). The hardness of GO was 0.34 GPa and that for the GO/EDA coatings was 1.14, 0.41, 0.39, and $0.40 \mathrm{GPa}$ for $5 \mathrm{~min}, 1 \mathrm{~h}, 3 \mathrm{~h}$, and $24 \mathrm{~h}$ of exposure, respectively. The elastic modulus of GO was $8.78 \mathrm{GPa}$ and that of the GO/EDA coatings was $28.7,8.68,7.13$, and 10.2 for EDA exposure times of $5 \mathrm{~min}, 1 \mathrm{~h}, 3 \mathrm{~h}$, and $24 \mathrm{~h}$, respectively. Both hardness and elastic modulus of the GO/EDA coating were relatively higher than those of GO. The highest values of hardness and elastic modulus were observed at EDA vapor exposure for $5 \mathrm{~min}$. It appeared that the mechanical properties of GO were highly enhanced when low amounts of EDA were present to crosslink adjacent GO sheets. In contrast, excessive EDA hindered the crosslinking by decorating the surface of GO as evidenced by the SEM image shown in Fig. 1E. 

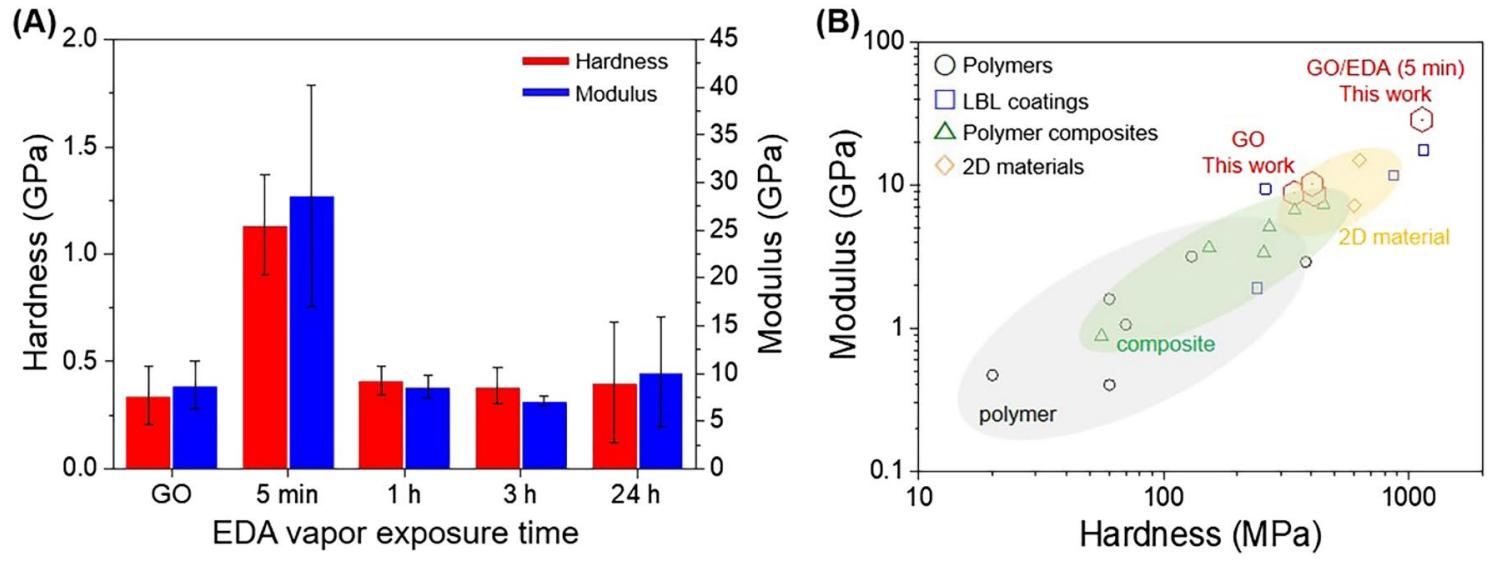

Figure 5. (A) The hardness and modulus of GO/EDA coatings measured by the nanoindentation technique and the average values were obtained from 3 to 5 points for each sample. (B) Mechanical properties comparison between GO/EDA coating and various coating materials.

The mechanical properties of the GO/EDA films (marked with red hexagons) are higher than polymers, polymer composite films, LBL films, and two-dimensional (2D) materials as summarized in Fig. 5B and Supplementary Table $\mathrm{S1}^{4,33,42-55}$. The hardness and modulus of polymer were reported as in the range of 20-380 MPa and 0.4-2.9 GPa. The hardness and the modulus of polymer composite films (green triangles) were in the range of 56-1510 MPa and 0.26-7.35 GPa, respectively. As expected, LBL film (blue squares) had better mechanical properties as 240-1150 MPa for hardness and 1.9-17.64 GPa for modulus. Neat 2D materials such as $\mathrm{MoS}_{2}$ showed hardness and modulus between 600-630 MPa and 7.2-15 GPa, respectively. Although various coating materials generally express adequate mechanical properties, the mechanical properties of GO/EDA coating are excellent particularly at 5 min of EDA exposure time with $1135 \mathrm{MPa}$ for hardness and $28.7 \mathrm{GPa}$ for modulus, which is beneficial for the utilization of the GO/EDA coating in high-pressure conditions such as high-pressure $\mathrm{H}_{2}$ storage tank.

While GO coating is known as an impermeable gas barrier ${ }^{23}$, the stability of GO in water is one of the critical problems associated with the use of the GO film in humid conditions or aqueous solvents ${ }^{56}$. Thereby, the stability of the GO/EDA coating in water, acidic solution, and basic solution was tested as shown in Fig. 6 . The concentration of acidic and basic solutions was $1 \mathrm{M}$, which was controlled by the volumes of $\mathrm{HCl}$ and $\mathrm{NaOH}$, respectively. A neat GO film on the nylon substrate was unstable and easily re-dispersed in water due to the abundant oxygen functional groups on the surface of $\mathrm{GO}^{57}$. In contrast, $\mathrm{GO} / \mathrm{EDA}$ coating on the nylon support was stable in water, acidic conditions, and basic conditions even after 15 days of immersion. The stability of the GO/EDA coating can be attributed to the crosslinking between GO sheets and EDA molecules as well as enhanced $\pi-\pi$ interaction between partially reduced GO sheets as discussed in Fig. 4.

The gas permeance of GO/EDA coating was measured using a time lag method with the equipment illustrated in Supplementary Fig. S6 (Fig. 7). A 75- $\mu$ m-thick PET film, one of the most widely used polymers for packaging, was used as a substrate film and the thickness of GO and GO/EDA coating was approximately 1-1.5 $\mu \mathrm{m}$ (Supplementary Fig. S7). First, the variation of the He permeance with EDA exposure time was measured to verify the influence of EDA amounts on the gas permeance of the GO/EDA coating and to evaluate the best GO/EDA structure to block gas permeation (Fig. 7A). (number) denotes the EDA exposure time of GO/EDA sample. The transmembrane pressure was 1 bar and the temperature was $25^{\circ} \mathrm{C}$. As previously reported ${ }^{23,33}$, the GO film was highly impermeable to He with a permeance of $9.58 \times 10^{-12} \mathrm{~mol} / \mathrm{m}^{2} \mathrm{~s} \mathrm{~Pa}$, which represents a $98.3 \%$ reduction to the neat PET film $\left(5.54 \times 10^{-10} \mathrm{~mol} / \mathrm{m}^{2} \mathrm{~s} \mathrm{~Pa}\right)$. The He permeances for GO/EDA $(5 \mathrm{~min}),(1 \mathrm{~h}),(3 \mathrm{~h})$, and $(24 \mathrm{~h})$ were $3.60 \times 10^{-11}, 3.75 \times 10^{-11}, 2.85 \times 10^{-11}$, and $2.23 \times 10^{-11} \mathrm{~mol} / \mathrm{m}^{2} \mathrm{~s} \mathrm{~Pa}$, respectively. Note that the permeance of GO/EDA coating is slightly higher than that of GO coating possibly due to the expanded interlayer spacing in the presence of EDA. Nonetheless, all GO/EDA coatings can enhance barrier properties of PET film, and the best $\mathrm{He}$ barrier performance was achieved at $24 \mathrm{~h}$ of EDA exposure time, showing a $96.0 \%$ reduction compared to the neat PET film.

The neat PET film, neat GO, and GO/EDA (24 h) coating were further tested with several gases including He, $\mathrm{H}_{2}, \mathrm{CO}_{2}, \mathrm{~N}_{2}$, and $\mathrm{CH}_{4}$ at 1 bar and $25^{\circ} \mathrm{C}$ (Fig. 7B). The neat PET film was permeable to all tested gas molecules showing a permeance in the range of $3.87 \times 10^{-10} \mathrm{~mol} / \mathrm{m}^{2} \mathrm{~s} \mathrm{~Pa}\left(\mathrm{CO}_{2}\right)-5.54 \times 10^{-10} \mathrm{~mol} / \mathrm{m}^{2} \mathrm{~s} \mathrm{~Pa}(\mathrm{He})$. Neat GO films were highly impermeable to all gas molecules, showing permeance in the range of $3.46 \times 10^{-12} \mathrm{~mol} / \mathrm{m}^{2} \mathrm{~s} \mathrm{~Pa}$ $\left(\mathrm{CO}_{2}\right)-9.58 \times 10^{-12} \mathrm{~mol} / \mathrm{m}^{2} \mathrm{~s} \mathrm{~Pa}(\mathrm{He})$, which represents a minimum $98.5 \%$ reduction for $\mathrm{H}_{2}$ and up to $99.1 \%$ reduction for $\mathrm{CO}_{2}$ compared to PET. Interestingly, the GO/EDA $(24 \mathrm{~h})$ film was also showed its highly impermeable property to different gas molecules with permeance ranging from $2.23 \times 10^{-11}$ to $7.12 \times 10^{-12} \mathrm{~mol} / \mathrm{m}^{2} \mathrm{~s} \mathrm{~Pa}$. The reduction degree compared to PET was approximately $98.5 \%$ for $\mathrm{H}_{2}$ and $99.0 \%$ for $\mathrm{CO}_{2}$ and the permeance reduction was particularly dramatic for gas molecules lager than $\mathrm{He}$ and $\mathrm{H}_{2}$. As indicated by the permeance tendency of all five gas molecules, the GO/EDA $(24 \mathrm{~h})$ film possessed a similar gas barrier performance to that of the neat GO film, which is known to have excellent gas barrier performance ${ }^{23}$. 


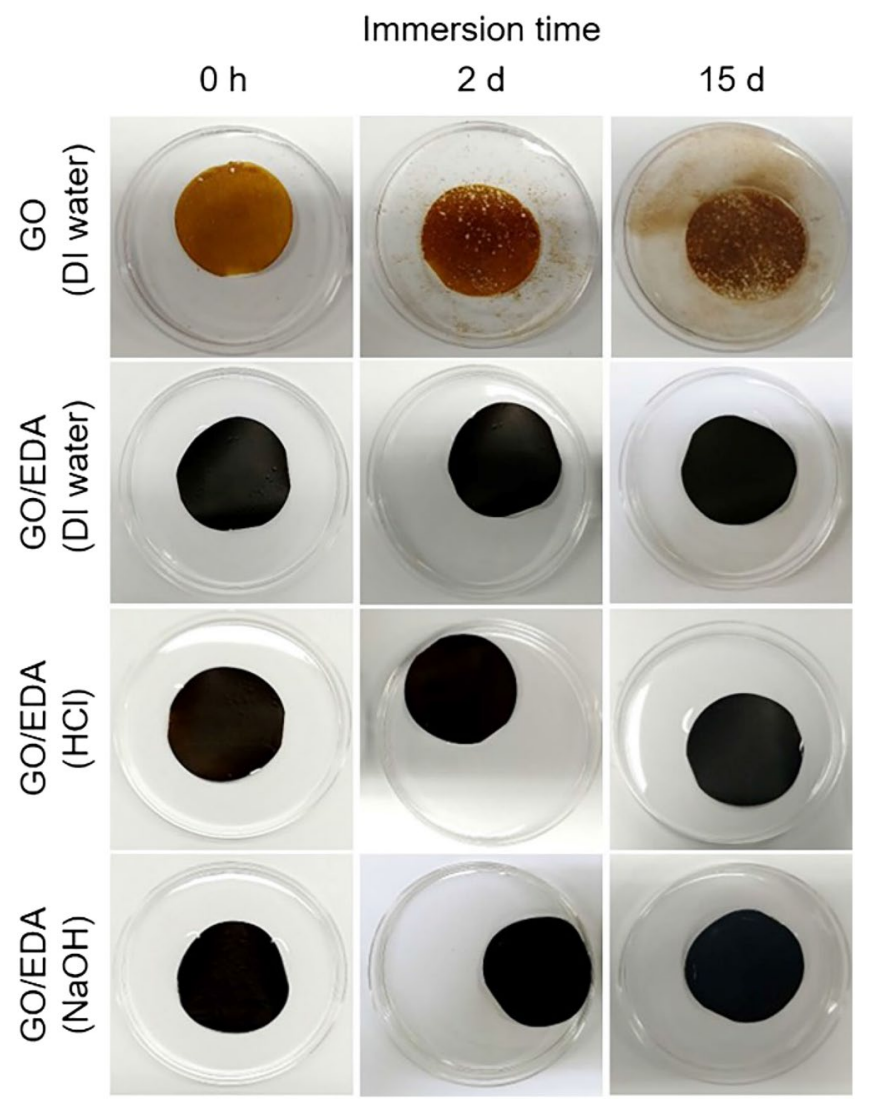

Figure 6. Stability of GO and GO/EDA coatings in aqueous solvents including water. The exposure time of EDA was $1 \mathrm{~h}$. The concentration of $\mathrm{HCl}$ and $\mathrm{NaOH}$ solutions was $1 \mathrm{M}$.

He permeance of GO/EDA ( $24 \mathrm{~h}$ ) was also examined by increasing the transmembrane pressure from 1 to 5 bar at room temperature $\left(25^{\circ} \mathrm{C}\right)$ as shown in Fig. 7C. While the He permeance of the neat PET film increased from $5.54 \times 10^{-10}$ to $3.06 \times 10^{-9} \mathrm{~mol} / \mathrm{m}^{2} \mathrm{~s}$ Pa for 1 and $5 \mathrm{bar}$, respectively, the He permeance of GO/EDA $(24 \mathrm{~h})$ decreased from $2.23 \times 10^{-11}$ to $4.11 \times 10^{-12} \mathrm{~mol} / \mathrm{m}^{2} \mathrm{~s}$ Pa for 1 and $5 \mathrm{bar}$, respectively, and a similar tendency was detected for neat GO. Therefore, the GO/EDA coating is particularly effective to block gas molecules at high pressure with a $99.3 \%$ reduction of He permeance at 5 bar compared to neat PET.

The influence of temperature on the He permeance of the GO/EDA ( $24 \mathrm{~h}$ ) film was investigated by increasing the temperature from 25 to $100^{\circ} \mathrm{C}$ and back to $25^{\circ} \mathrm{C}$ (Fig. 7D). The He permeance of neat GO gradually increased from $9.58 \times 10^{-12} \mathrm{~mol} / \mathrm{m}^{2} \mathrm{~s} \mathrm{~Pa}$ at $25^{\circ} \mathrm{C}$ to $2.59 \times 10^{-10} \mathrm{~mol} / \mathrm{m}^{2} \mathrm{~s} \mathrm{~Pa}$ at $100^{\circ} \mathrm{C}$ as indicated by the blue line in Fig. 7D. The GO/EDA ( $24 \mathrm{~h})$ film also showed a similar tendency with increased He permeance from $2.23 \times 10^{-11}$ to $3.19 \times 10^{-10} \mathrm{~mol} / \mathrm{m}^{2} \mathrm{~s}$ Pa at $25^{\circ} \mathrm{C}$ and $100^{\circ} \mathrm{C}$, respectively, which can be attributed to activated gas diffusion at high temperature, as previously reported for a laminated GO film ${ }^{33,58,59}$. After cooling to $25^{\circ} \mathrm{C}$, the He permeance of the GO coated film $\left(9.31 \times 10^{-12} \mathrm{~mol} / \mathrm{m}^{2} \mathrm{~s} \mathrm{~Pa}\right)$ was nearly the same as the value before heat treatment $\left(9.58 \times 10^{-12} \mathrm{~mol} / \mathrm{m}^{2} \mathrm{~s} \mathrm{~Pa}\right)$. In contrast, the He permeance of GO/EDA $(24 \mathrm{~h})$ was further reduced to $2.14 \times 10^{-12} \mathrm{~mol} / \mathrm{m}^{2} \mathrm{~s}$ Pa after cooling. Interestingly, this value is even lower than that of neat GO film, emphasizing that the additional heat treatment of GO/EDA $(24 \mathrm{~h})$ is effective in further enhancing the gas barrier properties of the GO/EDA coating.

To understand the origin of the enhanced gas barrier properties of GO/EDA (24 h) after heat treatment, additional experiments were conducted as shown in Supplementary Fig. S8. XRD patterns, Raman spectra, FT-IR spectra, and XPS C1s spectra of GO/EDA $(24 \mathrm{~h})$ after heat treatment at $100{ }^{\circ} \mathrm{C}$ demonstrated a better alignment of the GO nanosheets. This can be explained by the rearrangement of EDA between GO nanosheets, as a narrow interlayer spacing can be formed by the reduction of some of the oxygen-containing groups of GO (Supplementary Fig. S8). In addition, excessive and unreacted EDA molecules can be possibly removed from the composite film. Therefore, the enhanced gas barrier performance of GO/EDA $(24 \mathrm{~h})$ after heat treatment can be attributed to the abundantly arranged EDA molecules in the narrow nanochannels of GO, which hinder the diffusion of gas molecules by steric hindrance and hydrogen bonding interaction of polar molecules $\mathrm{s}^{3,33,60}$. In contrast, the low amount of EDA can increase the space of the nanochannels, resulting in faster gas permeation than neat GO, which happens in the case of GO/EDA ( $5 \mathrm{~min}$ ) shown in Fig. 7A. Therefore, controlling the interlayer spacing of GO and the amount of intercalated EDA is critical for achieving gas barrier performance.

The barrier performance of the GO/EDA $(24 \mathrm{~h})$ film is comparable with previous graphene-based gas barrier coatings as shown in Supplementary Table S2 $2^{3,4,10,13,24,32,61-63}$. Since experimental conditions such as coating 

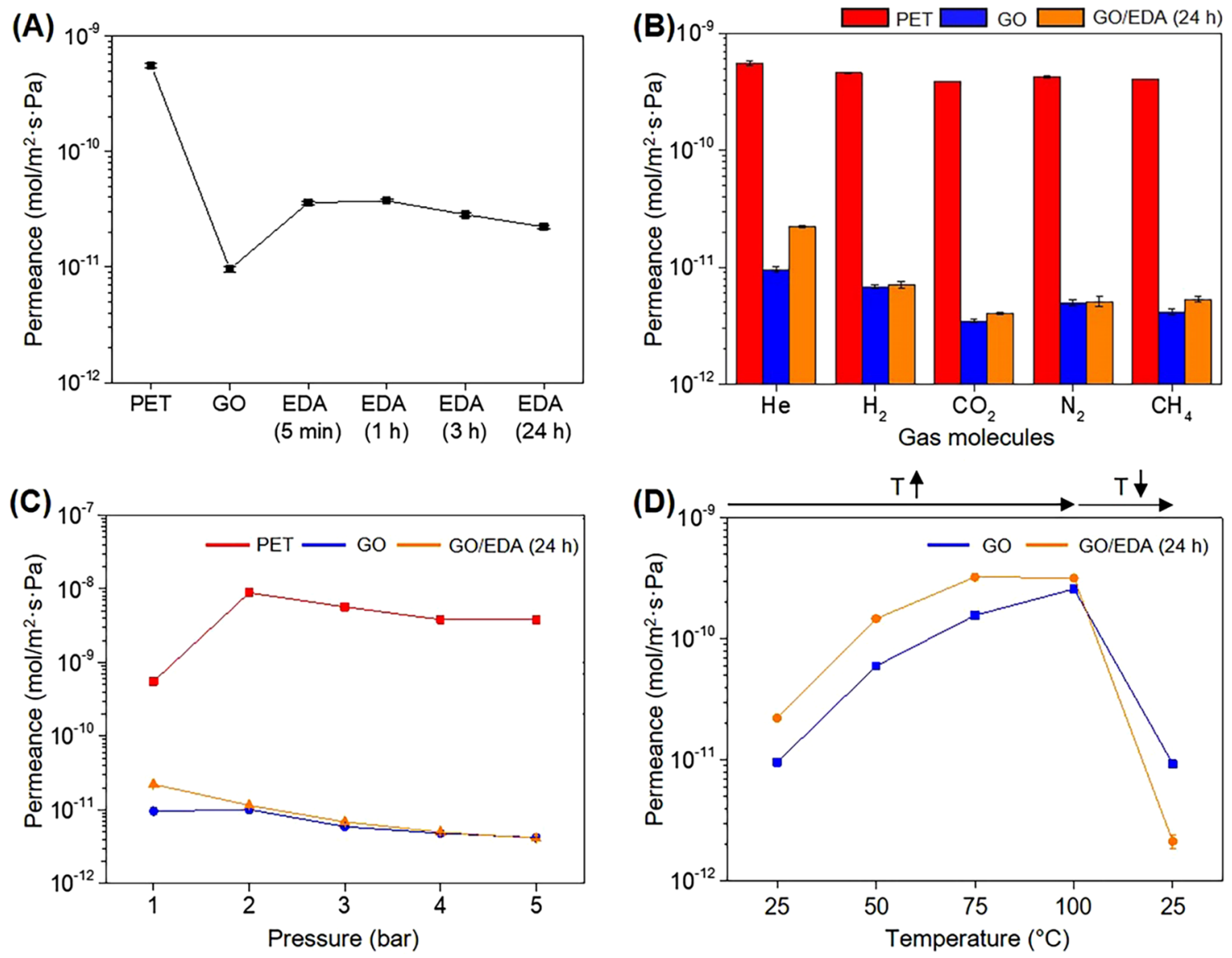

Figure 7. (A) He gas permeance of PET and GO/EDA depending on EDA exposure time. The thickness of GO was approximately $1 \mu \mathrm{m}$. (B) Gas permeances of neat PET, GO coated PET, and GO/EDA ( $24 \mathrm{~h}$ ) coated PET. (C) He gas permeance of PET, GO coated PET, and GO/EDA (24 h) coated PET as a function of pressure. (D) He gas permeance of GO and GO/EDA $(24 \mathrm{~h})$ coated PET as a function of temperature. Each point represents the average of a minimum of three measurements.

thickness, coating methods, and coating materials are different, it is hard to compare the gas barrier performance directly. Nevertheless, the comparison could be helpful to understand the effectiveness of the GO/EDA coating to block gas molecules. The permeance reduction of $\mathrm{He}$ and $\mathrm{H}_{2}$ was particularly organized because they are the smallest molecules and highly permeable and because there is a growing demand for the hydrogen storage tank with light materials. Simply mixed graphene/polymer coating shows $82-99.9 \%$ reduction of $\mathrm{H}_{2}$ permeance when applied onto PET or nylon substrates $3,4,10,13,24,32,62-64$. As expected, graphene-coatings prepared by LBL methods and neat rGO coating have reported high gas barrier performances with approximately $41.1-99.9 \%$ reduction of $\mathrm{H}_{2}$ and $\mathrm{He}$ permeance ${ }^{24,64}$. While our GO/EDA coating procedure is simple and readily applicable for coating various objects, the coating surpasses the performances of the aforementioned graphene polymer composites coating with a reduction of $99.6 \%$ and $98.5 \%$ in the permeances of $\mathrm{He}$ and $\mathrm{H}_{2}$, respectively.

\section{Conclusions}

We demonstrated that a highly concentrated GOLC system is effective to prepare composite materials based on graphene/small molecules. Since GOLC facilitates the diffusion of EDA through the macropores of its scaffolds and EDA is highly volatile even at low temperatures, intercalation and crosslinking of EDA between graphene sheets can be achieved spontaneously. Furthermore, the viscoelastic properties of GOLC are beneficial to coat well-aligned graphene sheets on the target surface. The intercalated EDA acts as a cross-linker and as a reducing agent; thus, the GO/EDA coating is highly stable in water, acids, and bases. The gas barrier performance of the GO/EDA film can be enhanced than that of neat GO film when the GO/EDA ( $24 \mathrm{~h})$ coating was heat-treated at $100{ }^{\circ} \mathrm{C}$. The heat-treated GO/EDA $(24 \mathrm{~h})$ film showed a permeance reduction of $99.6 \%$ and $98.5 \%$ for He and $\mathrm{H}_{2}$, respectively, at atmospheric conditions compared to a neat PET film. We believe this coating strategy can provide insight into the preparation of other 2D material-based multifunctional composite films and this method is also useful for the fabrication of hydrogen storage containers. 


\section{Methods}

GO synthesis. Graphite $(\leq 20 \mu \mathrm{m}, 99 \%$ pure, Sigma Aldrich) was oxidized using a modified Hummer's method by following the literature ${ }^{27}$. Graphite $(4 \mathrm{~g})$ and $\mathrm{KMnO}_{4}(12 \mathrm{~g})$ were mixed with $150 \mathrm{~mL}$ of sulfuric acid (98\%). After stirring the solution for $5 \mathrm{~h}$ at $35^{\circ} \mathrm{C}$, deionized (DI) water and hydrogen peroxide $\left(\mathrm{H}_{2} \mathrm{O}_{2}\right)$ were added in sequence, in an ice bath. The solution was then filtrated with a cellulose filter to remove any remaining acidic solution and washed several times with DI water. The filtrated GO was re-dispersed with DI water and freeze-dried to obtain GO powder.

Fabrication of the GO/EDA film. GO (3 g) was dispersed in $100 \mathrm{~mL}$ of DI water by ultrasonication for $3 \mathrm{~h}$ to prepare $30 \mathrm{mg} / \mathrm{mL}$ of GO solution. At the concentration, LC phase was observed by using polarized optical microscopy ${ }^{33}$. A nylon substrate (Sterlitech, $0.1 \mu \mathrm{m}$ pore diameter) and a polyethylene terephthalate (PET) film (75 $\mu \mathrm{m}$ thickness) were coated with GOLC to a thickness of $180 \mu \mathrm{m}$. The thickness was controlled using a bar-coater (Yoshimitsu, YBA-7). The substrates coated with GOLC were exposed to EDA vapor generated from an EDA solution $(75 \%, 0.5 \mathrm{~mL})$ for different exposure times $(1,5$, and $10 \mathrm{~min}, 1,24,45$, and $72 \mathrm{~h})$ at $50{ }^{\circ} \mathrm{C}$. The volatility of EDA accelerates its migration from the EDA solution into the GOLC coating. After exposure to the EDA vapor, the GO/EDA coated substrates were dried at $25^{\circ} \mathrm{C}$ for $24 \mathrm{~h}$ to remove the excess water.

Gas permeance measurement. Gas permeance was measured by a constant volume and differential pressure method by following the literature ${ }^{64,65}$, which is one of the most widely used techniques for measuring gas permeance. Films were placed on a stainless-steel mesh support and fixed using epoxy glue before the measurement. The sample cell was divided into two parts, the film side and mesh side. The mesh was under vacuum while the target gas was flowing on the other side with a flow rate of $20 \mathrm{sccm}$. The pressure of feed gas was controlled by using a backpressure regulator and a gas cylinder regulator. The vacuum of the permeation side was measured by using a vacuum gauge (Teledyne Hastings Instruments, HVG-2020B). The gas permeance was calculated with the following equation:

$$
\text { Permeance }=\frac{V_{c}}{R * T * P_{a} * A} \frac{d p}{d t}
$$

where $V_{C}$ is the chamber volume of the vacuum side $(98.5 \mathrm{~mL}), A$ is the effective film area $\left(\mathrm{m}^{2}\right), \mathrm{P}_{\mathrm{a}}$ is the atmospheric pressure or transmembrane pressure $(\mathrm{Pa}), \mathrm{dp} / \mathrm{dt}$ is the pressure variation of the chamber on the vacuum side per unit of time, and $\mathrm{R}$ is the gas constant. $\mathrm{T}$ is the temperature $(\mathrm{K})$, which was controlled using a convection oven.

Characterization. Scanning electron microscopy (SEM) images were obtained using a Field Emission Scanning Electron Microscopy (FE-SEM, JEOL, 7610f-plus). The viscosities of GO solutions were measured with a cone plate geometry (diameter: $40 \mathrm{~mm}$; angle: $1^{\circ} 58^{\prime} 55^{\prime \prime}$ ) and a Peltier plate temperature system of a discovery hybrid rheometer (DHR-3, TA Instruments) at $25^{\circ} \mathrm{C}$. Flow sweep tests were conducted with shear rates between $10^{-5}$ and $100 \mathrm{~s}^{-1}$ and a fixed truncation gap of $55 \mu \mathrm{m}$. X-ray diffraction (XRD) patterns were obtained using a SmartLab (Rigaku, wavelength: $1.54 \AA$ ) diffractometer. Water contact angle images were measured using an Attension Theta Lite (Biolin Scientific) optical tensiometer. Fourier-transform infrared (FT-IR) spectra were obtained using a Spectrum 100 (Perkin Elmer, USA). X-ray photoelectron spectroscopy (XPS) measurement was performed using a K-alpha (Thermo Fisher Scientific) with a $\mathrm{Cu}(\mathrm{Ka})$ beam source (wavelength $1.5406 \AA$ ). Nanoindentation tests were conducted using a nanoindentation system (Nano Indenter XP, MTS). Raman spectra were obtained using a LabRam Aramis (Horriba Jovin Yvon) with a $532 \mathrm{~nm}$ laser.

Received: 23 November 2020; Accepted: 20 April 2021

Published online: 04 May 2021

\section{References}

1. Lai, C. et al. Bio-inspired cross-linking with borate for enhancing gas-barrier properties of poly(vinyl alcohol)/graphene oxide composite films. Carbon 82, 513-522 (2015).

2. Singh Raman, R. K. et al. Protecting copper from electrochemical degradation by graphene coating. Carbon 50, 4040-4045 (2012).

3. Yang, Y. H., Bolling, L., Priolo, M. A. \& Grunlan, J. C. Super gas barrier and selectivity of graphene oxide-polymer multilayer thin films. Adv. Mater. 25, 503-508 (2013)

4. Li, X., Bandyopadhyay, P., Guo, M., Kim, N. H. \& Lee, J. H. Enhanced gas barrier and anticorrosion performance of boric acid induced cross-linked poly(vinyl alcohol-co-ethylene)/graphene oxide film. Carbon 133, 150-161 (2018).

5. Bunch, J. S. et al. Impermeable atomic membranes from graphene sheets. Nano Lett. 8, 2458-2462 (2008).

6. Kim, K. S. et al. Large-scale pattern growth of graphene films for stretchable transparent electrodes. Nature 457, 706-710 (2009).

7. Ma, Y. \& Zhi, L. Graphene-based transparent conductive films: Material systems, preparation and applications. Small Methods 3, 20 (2019).

8. Chen, S. et al. Oxidation resistance of graphene-coated $\mathrm{Cu}$ and $\mathrm{Cu} / \mathrm{Ni}$ alloy. ACS Nano 5, 1321-1327 (2011).

9. Kim, D. W., Kim, Y. H., Jeong, H. S. \& Jung, H. Direct visualization of large-area graphene domains and boundaries by optical birefringency. Nat. Nanotechnol. 7, 29-34 (2012).

10. Layek, R. K., Das, A. K., Park, M. U., Kim, N. H. \& Lee, J. H. Layer-structured graphene oxide/polyvinyl alcohol nanocomposites: Dramatic enhancement of hydrogen gas barrier properties. J. Mater. Chem. A 2, 20 (2014).

11. Kim, K. H. et al. The role of layer-controlled graphene for tunable microwave heating and its applications to the synthesis of inorganic thin films. ACS Appl. Mater. Interfaces 8, 5556-5562 (2016). 
12. Layek, R. K. et al. Layered structure graphene oxide/methylcellulose composites with enhanced mechanical and gas barrier properties. J. Mater. Chem. A 6, 13203-13214 (2018).

13. Li, X., Bandyopadhyay, P., Nguyen, T. T., Park, O. \& Lee, J. H. Fabrication of functionalized graphene oxide/maleic anhydride grafted polypropylene composite film with excellent gas barrier and anticorrosion properties. J. Membr. Sci. 547, 80-92 (2018).

14. Zhu, Y. et al. Graphene and graphene oxide: Synthesis, properties, and applications. Adv. Mater. 22, 3906-3924 (2010).

15. Xiang, C. et al. Functionalized low defect graphene nanoribbons and polyurethane composite film for improved gas barrier and mechanical performances. ACS Nano 7, 10380-10386 (2013).

16. Choi, K. et al. Reduced water vapor transmission rate of graphene gas barrier films for flexible organic field-effect transistors. ACS Nano 9, 5818-5824 (2015).

17. Choi, D., Park, H., Lim, J. H., Han, T. H. \& Park, J. Three-dimensionally stacked $\mathrm{Al}_{2} \mathrm{O}_{3}$ /graphene oxide for gas barrier applications. Carbon 125, 464-471 (2017)

18. Tölle, F. J., Gamp, K. \& Mülhaupt, R. Scale-up and purification of graphite oxide as intermediate for functionalized graphene. Carbon 75, 432-442 (2014).

19. Zhong, Y. L., Tian, Z., Simon, G. P. \& Li, D. Scalable production of graphene via wet chemistry: Progress and challenges. Mater. Today 18, 73-78 (2015).

20. Wei, P. \& Bai, S. Fabrication of a high-density polyethylene/graphene composite with high exfoliation and high mechanical performance via solid-state shear milling. RSC Adv. 5, 93697-93705 (2015).

21. Stankovich, S. et al. Synthesis of graphene-based nanosheets via chemical reduction of exfoliated graphite oxide. Carbon 45, 1558-1565 (2007).

22. Geng, Y., Wang, S. J. \& Kim, J. K. Preparation of graphite nanoplatelets and graphene sheets. J. Colloid Interface Sci. 336, 592-598 (2009).

23. Nair, R., Wu, H., Jayaram, P., Grigorieva, I. \& Geim, A. Unimpeded permeation of water through helium-leak-tight graphene-based membranes. Science 335, 442-444 (2012).

24. Su, Y. et al. Impermeable barrier films and protective coatings based on reduced graphene oxide. Nat. Commun. 5, 4843 (2014).

25. Kim, H. W. et al. High-performance $\mathrm{CO}_{2}$-philic graphene oxide membranes under wet-conditions. Chem. Commun. 50, 1356313566 (2014).

26. Pham, V. H. et al. Fast and simple fabrication of a large transparent chemically-converted graphene film by spray-coating. Carbon 48, 1945-1951 (2010).

27. Kim, D. W., Choi, J., Kim, D. \& Jung, H. Enhanced water permeation based on nanoporous multilayer graphene membranes: The role of pore size and density. J. Mater. Chem. A 4, 17773-17781 (2016).

28. Pierleoni, D. et al. Graphene-based coatings on polymer films for gas barrier applications. Carbon 96, 503-512 (2016).

29. Cruz-Silva, R. et al. Super-stretchable graphene oxide macroscopic fibers with outstanding knotability fabricated by dry film scrolling. ACS Nano 8, 5959-5967 (2014).

30. Moon, I. K. et al. 2D graphene oxide nanosheets as an adhesive over-coating layer for flexible transparent conductive electrodes. Sci. Rep. 3, 1-7 (2013).

31. Kim, J. H. et al. Scalable fabrication of deoxygenated graphene oxide nanofiltration membrane by continuous slot-die coating. J. Membr. Sci. 612, 20 (2020).

32. Liu, H. et al. Layer-by-layer assembled polyelectrolyte-decorated graphene multilayer film for hydrogen gas barrier application. Compos. B. Eng. 114, 339-347 (2017).

33. Kim, D. W., Kim, H., Jin, M. L. \& Ellison, C. J. Impermeable gas barrier coating by facilitated diffusion of ethylenediamine through graphene oxide liquid crystals. Carbon 148, 28-35 (2019).

34. Crisp, M. T. \& Kotov, N. A. Preparation of nanoparticle coatings on surfaces of complex geometry. Nano Lett. 3, 173-177 (2003).

35. Cui, Y., Kumar, S., Rao Kona, B. \& van Houcke, D. Gas barrier properties of polymer/clay nanocomposites. RSC Adv. 5, 6366963690 (2015).

36. Kim, J. E. et al. Graphene oxide liquid crystals. Angew. Chem. Int. Ed. 50, 3043-3047 (2011).

37. Kim, H. et al. Polydopamine-graphene oxide flame retardant nanocoatings applied via an aqueous liquid crystalline scaffold. $A d v$. Funct. Mater. 28, 1803172 (2018).

38. Kumar, P., Maiti, U. N., Lee, K. E. \& Kim, S. O. Rheological properties of graphene oxide liquid crystal. Carbon 80, 453-461 (2014).

39. Sasikala, S. P. et al. Graphene oxide liquid crystals: A frontier 2D soft material for graphene-based functional materials. Chem. Soc. Rev. 47, 6013-6045 (2018).

40. Hung, W. et al. Cross-linking with diamine monomers to prepare composite graphene oxide-framework membranes with varying d-spacing. Chem. Mater. 26, 2983-2990 (2014).

41. Kim, N. H., Kuila, T. \& Lee, J. H. Simultaneous reduction, functionalization and stitching of graphene oxide with ethylenediamine for composites application. J. Mater. Chem. A 1, 1349-1358 (2013).

42. Dhakal, H. N., Zhang, Z. Y. \& Richardson, M. O. W. Nanoindentation behaviour of layered silicate reinforced unsaturated polyester nanocomposites. Polym. Test. 25, 846-852 (2006).

43. Das, B., Eswar Prasad, K., Ramamurty, U. \& Rao, C. N. Nano-indentation studies on polymer matrix composites reinforced by few-layer graphene. Nanotechnology 20, 125705 (2009).

44. King, J. A., Klimek, D. R., Miskioglu, I. \& Odegard, G. M. Mechanical properties of graphene nanoplatelet/epoxy composites. J. Appl. Polym. Sci. 128, 4217-4223 (2013).

45. Sharma, B., Shekhar, S., Gautam, S., Sarkar, A. \& Jain, P. Nanomechanical analysis of chemically reduced graphene oxide reinforced poly (vinyl alcohol) nanocomposite thin films. Polym. Test. 70, 458-466 (2018).

46. Shin, S., Kim, J. S., Kim, S. J., Kim, D. W. \& Jung, H. Polybenzoxazole/graphene nanocomposite for etching hardmask. J. Ind. Eng. Chem. 75, 296-303 (2019).

47. Zhao, X. et al. Alternate multilayer films of poly(vinyl alcohol) and exfoliated graphene oxide fabricated via a facial layer-by-layer assembly. Macromolecules 43, 9411-9416 (2010).

48. Tang, L., Li, X., Du, D. \& He, C. Fabrication of multilayer films from regenerated cellulose and graphene oxide through layer-bylayer assembly. Prog. Nat. Sci. 22, 341-346 (2012).

49. Wang, N., Ji, S., Zhang, G., Li, J. \& Wang, L. Self-assembly of graphene oxide and polyelectrolyte complex nanohybrid membranes for nanofiltration and pervaporation. Chem. Eng. J. 213, 318-329 (2012).

50. Hatter, C. B., Shah, J., Anasori, B. \& Gogotsi, Y. Micromechanical response of two-dimensional transition metal carbonitride (MXene) reinforced epoxy composites. Compos. B. Eng. 182, 20 (2020).

51. Panich, N., Wangyao, P., Hannongbua, S., Sricharoenchai, P. \& Sun, Y. Effect of polytetrafluoroethylene doping on tribological property improvement of $\mathrm{MoS}_{2}$ nano-thin films on Ti-substrate. Rev. Adv. Mater. Sci. 16, 88-95 (2007).

52. Fang, T. \& Chang, W. Nanoindentation characteristics on polycarbonate polymer film. Microelectron 35, 595-599 (2004).

53. Flores, A. et al. Structure formation in poly(ethylene terephthalate) upon annealing as revealed by microindentation hardness and X-ray scattering. Polymer 46, 9404-9410 (2005).

54. Gracias, D. \& Somorjai, G. Continuum force microscopy study of the elastic modulus, hardness and friction of polyethylene and polypropylene surfaces. Macromolecules 31, 1269-1276 (1998).

55. Gupta, T. K., Singh, B. P., Dhakate, S. R., Singh, V. N. \& Mathur, R. B. Improved nanoindentation and microwave shielding properties of modified MWCNT reinforced polyurethane composites. J. Mater. Chem. A 1, 20 (2013). 
56. Nam, Y. T., Choi, J., Kang, K. M., Kim, D. W. \& Jung, H. Enhanced stability of laminated graphene oxide membranes for nanofiltration via interstitial amide bonding. ACS Appl. Mater. Interfaces 8, 27376-27382 (2016).

57. Konios, D., Stylianakis, M. M., Stratakis, E. \& Kymakis, E. Dispersion behaviour of graphene oxide and reduced graphene oxide. J. Colloid Interface Sci. 430, 108-112 (2014).

58. Kim, H. W. et al. Selective gas transport through few-layered graphene and graphene oxide membranes. Science 342, 91-95 (2013).

59. Ibrahim, A. \& Lin, Y. S. Gas permeation and separation properties of large-sheet stacked graphene oxide membranes. J. Membr. Sci. 550, 238-245 (2018).

60. Kim, D. W. et al. Revealing the role of oxygen debris and functional groups on the water flux and molecular separation of graphene oxide membrane: A combined experimental and theoretical study. J. Phys. Chem. C 122, 17507-17517 (2018).

61. Bandyopadhyay, P. et al. Hexylamine functionalized reduced graphene oxide/polyurethane nanocomposite-coated nylon for enhanced hydrogen gas barrier film. J. Membr. Sci. 500, 106-114 (2016).

62. Bandyopadhyay, P., Nguyen, T. T., Li, X., Kim, N. H. \& Lee, J. H. Enhanced hydrogen gas barrier performance of diaminoalkane functionalized stitched graphene oxide/polyurethane composites. Compos. B. Eng. 117, 101-110 (2017).

63. Pierleoni, D. et al. Selective gas permeation in graphene oxide-polymer self-assembled multilayers. ACS Appl. Mater. Interfaces 10, 11242-11250 (2018).

64. Kim, D. W., Han, H., Kim, H., Guo, X. \& Tsapatsis, M. Preparation of a graphene oxide/faujasite composite adsorbent. Micropor. Mesopor. Mat. 268, 243-250 (2018).

65. Choi, E. et al. Pore tuning of metal-organic framework membrane anchored on graphene-oxide nanoribbon. Adv. Funct. Mater. 31, 2011146 (2021).

\section{Acknowledgements}

We gratefully acknowledge the support of basic science research program through the National Research Foundation of Korea funded by the Ministry of Education (NRF-2019R1A6A1A11055660). This research was also supported by the National Research Foundation of Korea (NRF) with funding from the Korean Government (MSIT) (NRF-2020R1C1C1003289), Yonsei University Research fund of 2019-22-0012 and an internal Grant (code: 20200543) from the Korea Institute of Civil Engineering and Building Technology (KICT).

\section{Author contributions}

D.W.K. designed and supervised the entire experiment; S.E.C. carried out all the experiments; D.W.K. and S.E.C. prepared the manuscript; D.W.K., S.E.C., Y.C. visualized the key idea of the experiment; D.W.K., S.E.C., S.K., J.H.K., J.K. analyzed the data, D.W.K., S.E.C., E.C., O.K. discussed the methodology; all authors discussed the results.

\section{Competing interests}

The authors declare no competing interests.

\section{Additional information}

Supplementary Information The online version contains supplementary material available at https://doi.org/ 10.1038/s41598-021-88955-5.

Correspondence and requests for materials should be addressed to D.W.K.

Reprints and permissions information is available at www.nature.com/reprints.

Publisher's note Springer Nature remains neutral with regard to jurisdictional claims in published maps and institutional affiliations.

(c) (i) Open Access This article is licensed under a Creative Commons Attribution 4.0 International (c) License, which permits use, sharing, adaptation, distribution and reproduction in any medium or format, as long as you give appropriate credit to the original author(s) and the source, provide a link to the Creative Commons licence, and indicate if changes were made. The images or other third party material in this article are included in the article's Creative Commons licence, unless indicated otherwise in a credit line to the material. If material is not included in the article's Creative Commons licence and your intended use is not permitted by statutory regulation or exceeds the permitted use, you will need to obtain permission directly from the copyright holder. To view a copy of this licence, visit http://creativecommons.org/licenses/by/4.0/.

(C) The Author(s) 2021 